\title{
Injuries and their prevention in the handball game Ioana Curitianu ${ }^{1}$, Elena Balint ${ }^{2}$
}

${ }^{1}$ Assistant PhD, Transilvania University of Brasov, Faculty of Physical Education and Mountain Sports, Department of Physical Education and Special Motility, No.1 Colina Universităţii Street, Brasov, 500068, Romania, Phone number - 0740455088 ioana.curitianu@gmail.com

${ }^{2}$ Professor, Transilvania University of Brasov, Faculty of Physical Education and Mountain Sports, Department of Physical Education and Special Motility, No.1 Colina Universităţii Street, Brasov, 500068, Romania, Phone number - 0746656113

ABSTRACT liabalint@gmail.com

Sport training involves repeated bouts of exercise and high volume of physically demanding practice sessions and competitive games, which may lead to decline on performance, oxidative stress, and inflammation (Margonis K. et. al., 2007, Finaud J. et. al., 2006).

Handball is considered a demanding exercise mode that places important stress on a player's aerobic metabolism. In addition, handball game involves a large number of anaerobic actions such as bodycontact, repeated accelerations, sprints, jumps, throwing, blocking, pushing, and rapid changes in moving directions (Ronglan L.T. et. al., 2006, Gorostiaga E.M. et. al., 2006).

Studies in elite handball players have focused only on performance parameters like maximal muscle strength, sprint time, and jump height in response to a tournament (Ronglan L.T. et. al., 2006). During a competitive handball season, the demand for playing two games per week elevates the stress imposed to the athletes, thereby increasing the injury risk and performance decline due to fatigue and muscle damage.

Most prevalent injuries in handball is today, without any doubt, an extremely traumatic sport and it will be getting even more so with reference to the increase of strength, speed, and rhythm of the game. Numerous injuries which occur during the training process and games do not differ greatly with reference to age and sex (Wedderkopp N. et. al., 1997, Junge A. et. al., 2004).

\section{Indexing terms/Keywords}

injuries, handball game, type of effort in handball

\section{Academic Discipline And Sub-Disciplines}

Sport sciences

\section{SUBJECT CLASSIFICATION}

Sport science

\section{TYPE (METHOD/APPROACH)}

Review article

\section{Council for Innovative Research}

\section{Peer Review Research Publishing System}

\section{Journal: Journal of Social Sciences Research}

Vol .7, No.2

jssreditor.cir@gmail.com

www.jssronline.com 


\section{INTRODUCTION}

Competitive team handball is an intermittent high intensity body-contact team sport that requires a combination of aerobic and anaerobic fitness to perform a sequence of well-coordinated activities (Buchheit M. et. al, 2009; Buchheit M. et. al, 2009; Rannou F. et. al., 2001, Souhail H. et. al., 2010). Performance in a variety of intermittent team sports has been linked to the participant's speed, power, strength, agility, and a sustained ability to repeat short increased intensity bursts of activity throughout a match, rather than the capacity to sustain a steady submaximal work rate (Bangsbo J. et. al., 1991). Team handball places a heavy emphasis on sprinting, running, jumping, and throwing (Gorostiaga E.M. et. al., 2005).

Handball is a sport with high anaerobic demands according to studies conducted in adults (Bayios I.A. et. al., 2001; Gorostiaga E.M. et. al., 2005; Izquierdo M. et. al., 2002, Rannou F. et. al., 2001). Many tasks during the handball game, like pushes, blockes, trows and hits, require high levels of strength and power not only in lower (Izquierdo M. et. al., 2002, Rannou F. et. al., 2001) but also in upper body segments. (Bayios I.A . et. al., 2001; Gorostiaga E.M. et. al., 2005; Izquierdo M. et. al., 2002).

Although technical skills, anthropometric characteristics and muscle strength and power are the most important factors for successful participation in elite levels of handball leagues (Gorostiaga E.M et. al., 2005; Rannou F. et. al., 2001) the importance of aerobic capacity should not be underestimated.

\subsection{Effort in the handball game}

During handball participation a great number of rapid directional changes, starts, stops, jumps and landing occur (Arjmandi, et al., 2010). A handball match involves a large number of repeated accelerations, sprints, jumps, blocking, pushing and rapid changes in moving directions, i.e. side cutting (Gorostiaga E.M. et al., 2006; Ronglan L.T. et al., 2006). The variety of complex movement structures inherent to handball requires a specific and high level of physical and physiological conditioning (Gorostiaga et al., 2006).

Therefore, handball is a sport characterized by the involvement of both aerobic and anaerobic metabolic pathways and high levels of blood lactate may sometimes be observed during a match (Ronglan et al., 2006). The ability to repeat high intensity efforts may be of importance for handball players. Several studies have suggested that lactate accumulation is associated with muscular fatigue (Ahmaidi et al., 1996).

Also, it was revealing that the ability to perform maximally during repeated exercise bouts is influenced by the nature of both exercise and recovery periods (Greenwood et. al, 2008).

A recent study on fatigue in elite female handball players focused only on performance parameters like maximal muscle strength, sprint time and jump height in response to a training camp or prolonged tournament (Ronglan L.T. et al., 2006). Previous reports have indicated that active recovery is better than passive recovery for blood lactate disappearance (Ahmaidi et al., 1996; Monedero J., Done B., 2000).

Researchers suggested that to be played successfully, team handball players should possess a well-developed anaerobic and aerobic fitness (Gorostiaga E.M. et. al., 2005; Rannou F. et. al., 2001). Consequently, the measurement of motor and physical tests performance was proposed for fitness assessment (Delamarche P., et. al., 1987; Gorostiaga E.M. et. al., 2006; Rannou F. et. al., 2001) and talent detection in team handball (Lidor R. Et. al., 2005). However, the articles that, with different purposes, addressed the issue of talent detection and development involving young team handball players only used short-term anaerobic tests and mainly explosive strength exercises (Gorostiaga E.M. et. al., 2006; Gorostiaga E.M. et. al., 2005; Lidor R. et. al., 2005).

Match analyses showed that team handball involves a great deal of intermittent high intensity activities that are undertaken by players throughout the game (Pers J. et. al., 2002). Therefore, the ability to perform repeatedly intermittent highintensity exercise for the entire duration of the game may be considered as a logical criterion in team handball training and testing. Additionally, training studies have reported the importance of intermittent high-intensity endurance in elitelevel team handball players (Gorostiaga E.M. et. al., 2005).

\subsection{Risk of injury for handball players}

Several authors have analyzed the incidence of injuries in a given type of sport, but the results of these studies cannot be compared with one another because of heterogeneous injury definitions, methods of data collection, observationstandardized injury report form.

A significantly higher percentage of noncontact $(57 \%)$ versus contact injuries (37\%) was expected to prevent the player from participating in his or her sport. Significantly more injuries in male players (46\%) versus female players (35\%) were expected to result in absence from match or training. The incidence, diagnosis and causes of injuries differed substantially between the team sports. periods, study designs, and sample characteristics. (Finch C.F., 1997; Junge A., Dvorak J., 2000).

As long as no consensus on a standardized assessment of sport injury is approved by the scientific community and the sports federations, the incidence and characteristics of injuries in different types of sport can best be compared within one study.

In reviewing the literature on sports injuries, we found only a few studies in which exposurerelated incidences of injury in different types of sport were compared using the same methods (Backx F.J. et. al., 1991; De Loes M., 1995; De Loes M., Goldie I. 1988; Junge A. et. al., 2004; Nicholl J.P et. al., 1995; Yde J. et. al., 1990).

The incidence of injuries monitored and studied by Nielsen and Yde (1988) was determined to be 4.6/1,000 of training hours and 11.4/1,000 game hours. It showed that the upper extremities were exposed to injuries in $41 \%$ of cases, including the incidence of $21 \%$ of finger injuries. 
Ankle sprain is the most frequent leg injury, accounting for $33 \%$ of the total injuries, while overstrain syndrome has the incidence of $18 \%$. Repeated exposure to the same mechanisms and burdens during trainings, as well as contests, results in a relative risk of repeated injury of $32 \%$ (Nielsen A.B., Yde J., 1988).

Numerous researches, but also everyday experiences showed that other joints are not immune either to injuries during handball game, not even those which are not quite represented in sports traumatology. It was showed that the elbow may also be the point of injury, although this type of injury most commonly affects handball goalkeepers.

Popovic N. and Lemaire R. (2002) conducted their study about elbow injuries on 30 top goal keepers. The specific nature of their trainings and preparations for extremely high burdening of this joint while blocking shots, when the handball flies at great speeds, leads also to the specific burdening of the elbow and wrist as well as the structures around the joints.

There is a big difference among burdens and also among risks of injuring each other at trainings and competitions. More precisely, during a training process, in spite of a wish for a contest and proving one's individual qualities in relation to fellow players, there is still solidarity within the team. That is why injuries, as well as their types and intensity, differ at trainings and during the competition period.

Seil et. al. (1998) studied the incidence of injuries at trainings and games in 186 subjects - handball players from 16 clubs. The incidence of injuries was much higher during games than in the course of trainings: 14.3 injuries/1,000 game hours in relation to $0.6 / 1,000$ hours of training. Upper extremities were represented in the total number with $37 \%$, and lower with $54 \%$. The most common injury was the knee injury, followed by finger, ankle, and shoulder injuries.

Olsen et. al. (2004) studied the connection of the cruciate ligament injury incidence and the ground surface played on, detecting higher injury risk on the artificial surface in relation to the wooden floor or parquet. The injuries of the cruciate ligament belong to more common knee injuries in handball and are related to abrupt direction changes and contact during play.

The injuries are located mostly at the upper extremities, with finger injuries and distortion of the ankle joint the injuries reported most frequently (Dirx M., Bouter L.M., 1989). Injuries may be dassified by their nature (distortion, sprains, etc.) and by site on the body. The nature of the injuries, as reported by the injured players, The factors for the occurrence of injurie: age, being older than 20 years, the experience of a player, not stretching out before a game, not warming up before playing

In some of the studies, injuries were assessed using retrospective questionnaires or interviews (Leidinger A. et al., 1990; Seil R. et al., 1997; Wedderkopp N. et al., 1997; Reckling C. et al., 2003), other documented prospectively injuries during the season (Nielsen A., Yde J., 1988; Yde J., Nielsen A., 1990; Backx F. et al., 1991; Seil R. et al., 1998; Wedderkopp N. et al., 1999; Olsen O. et al., 2005) and one study used video analysis (Oehlert K. et al., 2004).

However, most of the studies evaluated injuries (Nielsen A., Yde J., 1988; Yde \& Nielsen, 1990; Backx et al., 1991; Wedderkopp N. et al., 1997; Reckling et al., 2003) or the effects of preventive program (Wedderkopp N. et al., 1999; Olsen O. et al., 2005) in adolescent players. Only two studies reported prospective data on handball injuries of adult amateur players during the season (Nielsen A., Yde J., 1988; Seil R. et al., 1998), and two further studies analyzed injuries during international tournaments (Asembo J.M., Wekesa M., 1998; Oehlert K. et al., 2004).

A difference in the incidence of injury between male and female players as reported by Asembo and Wekesa (1998) was, only found for time loss injuries but not for all injuries. However, the injuries of female and male handball players were similar in almost all characteristics. The risk of injury in different playing positions, was previously reported by other authors (Wedderkopp N. et. al., 1997; Oehlert K. et. al., 2004).

The high number of head injuries in handball tournaments was previously observed by Asembo and Wekesa (1998) and Oehlert O. et al. (2004). In this context, it is important to mention that these studies did not restrict their injury definition to time loss. More than half of the injuries (59\%) incurred during the East and Central Africa Senior Clubs Championship 1995 affected the head Asembo and Wekesa (1998), and approximately one third (20 of 59) of the injuries analyzed from video tapes of the handball tournaments during the Olympic Games 1992 Oehlert K. et al. (2004). The proportion of head injuries declined to $18 \%$ if only time loss injuries were regarded. Head injuries are also reported as a major problem in a study from elite football clubs in Scandinavia (Andersen T.E. et al., 2004).

Recently published studies have shown that it is possible to prevent lower extremity injuries in handball (Petersen W. et al., 2002; Wedderkopp et al., 2003; Olsen O. et al., 2005). In a controlled-randomized study of youth handball players, the incidence of lower extremity injuries was significantly reduced by implementing a structured warm-up program to improve running, cutting and landing techniques as well as neuromuscular control, balance and strength (Olsen et al., 2005). It has been described previously that female handball players have an approximately five times higher risk of incurring a rupture of the anterior cruciate ligament than male players (Myklebust G. et al., 1997, 1998).

\section{Conclusions}

1. The substantially higher injury rate during tournaments of top-level players is probably caused by several factors, such as the higher speed of the game, the tougher play and the high number of matches during a short period of time.

2. Sport specific knowledge may facilitate the adjustment of more adequate training and competition procedures within elite handball.

3. Based on the high incidence of injuries found in different studies and the evolution of the handball game show the importance of fair play as an essential aspect in the prevention of injury. Close cooperation with the referees might help to make handball a safer sport.

4. Injuries are a major concern in most team sports, therefore, prevention should be a priority in all teams.

5. Injury surveillance can help to determine needs and possibilities for preventive interventions to make handball an even safer sport. 


\section{REFERENCES}

[1] Ahmaidi, S., Granier, P., Taoutaou, Z. (1996). Effects of active recovery on plasma lactate and anaerobic power following repeated intensive exercise. Medicine and Science in Sports and Exercise, 28(4), 450-456.

[2] Arjmandi, B., Rahnama, N., Bambaeichi, E., Khayambashi, K., Jafarpour, S.A. (2010) Comparison of bone mineral density values in professional female handball and futsal players and non-athletes. Medicine and Science in Sports and Exercise, 42, 702.

[3] Andersen, T.E., Arnason, A., Engebretsen, L., Bahr, R. (2004). Mechanisms of head injuries in elite football. Br. J. Sports Med. 38: 690-696.

[4] Asembo, J.M., Wekesa, M. (1998). Injury pattern during team handball competition in East Africa. East Afr. Med. J. 75: 113-116.

[5] Backx, F.J., Beijer, H.J., Bol, E., Erich, W.B. (1991). Injuries in high-risk persons and highrisk sports. A longitudinal study of 1818 school children. Am. J. Sports Med. 19: 124-130.

[6] Bayios, I.A., Anastasopoulou, E.M., Sioudris, D.S., Boudolos, K.D. (2001). Relationship between isokinetic strength of the internal and external shoulder rotators and ball velocity in team handball. J. Sports Med. Phys. Fitness. 41:229235.

[7] Bangsbo, J., Nørregaard, L., Thorso, F. (1991). Activity profile of competition soccer. Can. J. Sport Sci. 16: 110-116.

[8] Buchheit, M., Laursen, P.B., Kuhnle, J., Ruch, D., Renaud, C., Ahmaidi, S. (2009). Game-based training in young elite handball players. Int. J. Sports Med. 30: 251-258.

[9] Buchheit, M., Lepretre, P.M., Behaegel, A.L., Millet, G.P., Cuvelier, G., Ahmaidi, S. (2009). Cardiorespiratory responses during running and sportspecific exercises in handball players. J. Sci. Med. Sport 12: 399-405.

[10] De Loes, M. (1995). Epidemiology of sports injuries in the Swiss organization "Youth and Sports" 1987-1989: injuries, exposure and risks of main diagnoses. Int. J. Sports Med.16:134-138.

[11] Dirx, M., Bouter, L.M.(1989). Incidentie en etiologie van handbalblessures. Geneeskunde en Sport. 22: 43-6.

[12] Finch, C.F. (1997). An overview of some definitional issues for sports injury surveillance. Sports Med. 24:157-163.

[13] Finaud, J., Scislowski, V. , Lac G. (2006). Antioxidant status and oxidative stress in professional rugby players: evolution throughout a season. International Journal of Sports Medicine, vol. 27, no. 2, pp. 87-93.

[14] Gorostiaga, E. M. , Granados, C. , Ibanez, J. , GonzalezBadillo, J. J. , Izquierdo, M. (2006). Effects of an entire season on physical fitness changes in elite male handball players. Medicine and Science in Sports and Exercise. vol. 38, no. 2, pp. 357-366.

[15] Gorostiaga, E.M., Granados, C., Ibanez, J., Izquierdo, M. (2005). Differences in physical fitness and throwing velocity among elite and amateur male handball players. Int. J. Sports Med. 26: 225-232.

[16] Greenwood, J.G., Moses, G.E., Bernardino, F.M., Gaesser, G.A., \& Weltman, A. (2008). Intensity of exercise recovery, blood lactate disappearance, and subsequent swimming performance. J. Sport Sci. 26(1), 29-34.

[17] Izquierdo, M., Hakkinen, K., Gonzalez-Badillo, J., Ibanez, J., Gorostiaga, E.M. (2002). Effects of long term training specificity on maximal strength and power of the upper and lower extremities in athletes from different sports. Eur. J. Appl. Physiol. 87:264-271.

[18] Junge, A., Langevoort, G., Pipe, A., Peytavin, A., Wong, F., Mountjoy, M., Beltrami, G., Terrell, R., Holzgraefe, M., Charles, R., Dvorak, J.(2006). Injuries in team sport tournaments during the Olympic games 2004. Am. J. Sports Med. 34: 565-576.

[19] Junge, A., Cheung, K., Edwards, T., Dvorak, J. (2004).Injuries in youth amateur soccer and rugby players comparison of incidence and characteristics. Br. J. Sports Med. 38:168-72.

[20] Junge, A., Dvorak, J. (2000). Influence of definition and data collection on the incidence of injuries in football. Am. J. Sports Med. 28(suppl 5): S40-S46.

[21] Leidinger, A., Gast, W., Pforringer, W. (1990).Traumatology in indoor handball sports. A sports medicine analysis of the incidence of injuries and accident epidemiology of indoor handball sports in senior players in the federal republic of Germany after 1981. Sportverletz Sportschaden. 4: 65-68.

[22] Lidor, R., Falk, B., Arnon, M., Cohen, Y., Segal, G., Lander, Y. (2005). Measurement of talent in team handball: The questionable use of motor and physical tests. J. Strength Cond. Res. 19: 318-325.

[23] Margonis, K. , Fatouros, I. G., Jamurtas A. Z. (2007). Oxidative stress biomarkers responses to physical overtraining: Implications for diagnosis. Free Radical Biology and Medicine, vol. 43, no. 6, pp. 901-910.

[24] Monedero, J., Donne, B. (2000). Effect of recovery interventions on lactate removal and subsequent performance. Int. J. Sports Med., 21(8), 593-597.

[25] Myklebust, G., Maehlum, S., Engebretsen, L., Strand, T, Solheim, E. (1997). Registration of cruciate ligament injuries in Norwegian top level team handball. A prospective study covering two seasons. Scand. J. Med. Sci. Sports. 7: 289292. 
[26] Myklebust, G., Maehlum, S., Holm, I., Bahr, R. (1998). A prospective cohort study of anterior cruciate ligament injuries in Elite Norwegian team handball. Scand. J. Med. Sci. Sports. 8: 149-153.

[27] Nicholl, J.P., Coleman, P., Williams, B.T. (1995).The epidemiology of sports and exercise related injury in the United Kingdom. Br. J. Sports Med. 29:232-238.

[28] Nielsen, A.B., Yde, J. (1998). An epidemiologic and traumatologic study of injuries in handball. Int. J. Sports Med. 9: 341-344.

[29] Oehlert, K., Drescher, W., Petersen, W., Zantop, T., Gross, V., Hassenpflug, J. (2004). Injuries in Olympic handball tournaments: a video analysis. Sportverletz Sportschaden. 18: 80-84.

[30] Olsen, O.E., Myklebust, G., Engebretsen, L., Holme, I., Bahr, R. (2005). Exercises to prevent lower limb injuries in youth sports: cluster randomised controlled trial. Br. Med. J. 330: 449.

[31] Olsen, O.E., Myklebust, G., Engebretsen, L., Bahr, R.(2004). Injury mechanisms for anterior cruciate ligament injuries in team handball: a systematic video analysis. Am. J. Sports Med. 32:1002-12.

[32] Pers, J., Mart, A., Stanislav, K., Marko, D. (2002). Observation and analysis of large-scale human motion. Hum. Mov. Sci. 21: 295-311.

[33] Petersen, W., Zantop, T., Steensen, M., Hypa, A., Wessolowski, T., Hassenpflug, J. (2002). Prevention of lower extremity injuries in handball: initial results of the handball injuries prevention programme. Sportverletz Sportschaden. 16: 122-126.

[34] Popovic, N., Lemaire, R.(2002). Hyperextension trauma to the elbow: radiological and ultrasonographic evaluation in handball goalkeepers. Br. J. Sports Med. 36:452-6.

[35] Rannou, F., Prioux, J., Zouhal, H., Gratas-Delamarche, A., Delamarche, P. (2001). Physiological profile of handball players. J. Sports Med. Phys. Fitness 41: 349-353.

[36] Reckling, C., Zantop, T., Petersen, W. (2003). Epidemiology of injuries in juvenile handball players. Sportverletz Sportschaden. 17: 112-117.

[37] Ronglan, L. T. , Raastad, T. , Børgesen, A . (2006). Neuromuscular fatigue and recovery in elite female handball players. Scandinavian Journal of Medicine and Science in Sports, vol. 16, no. 4, pp. 267-273.

[38] Seil, R., Rupp, S., Tempelhof, S., Kohn, D. (1997). Injuries during handball: a comparative, retrospective study between regional and upper league. Sportverletz Sportschaden. 11: 58-62.

[39] Seil, R., Rupp, S., Tempelhof, S., Kohn, D. (1998). Sports injuries in team handball. A one-year prospective study of sixteen men's senior teams of a superior nonprofessional level. Am. J. Sports Med. 26: 681-687.

[40] Souhail, H., Castagna, C., Mohamed, H.Y., Younes, H., and Chamari, K. (2010). Direct validity of the Yo-Yo intermittent recovery test in young team handball players. J. Strength Cond. Res. 24: 465-470.

[41] Wedderkopp, N., Kaltoft, M., Holm, R., Froberg, K.(2003). Comparison of two intervention programmes in young female players in european handball - with and without ankle disc. Scand. J. Med. Sci. Sports. 13: 371-375.

[42] Wedderkopp, N., Kaltoft, M., Lundgaard, B., Rosendahl, M., Froberg, K. (1997). Injuries in young female players in European team handball. Scand. J. Med. Sci. Sports. 7: 342-347.

[43] Wedderkopp, N., Kaltoft, M., Lundgaard, B., Rosendahl, M., Froberg, K. (1999). Prevention of injuries in young female players in European team handball. A prospective intervention study. Scand. J. Med. Sci. Sports. 9: 41-47.

[44] Yde, J., Nielsen, A.B. (1990). Sports injuries in adolescents' ball games: soccer, handball and basketball. Br. J. Sports Med. 24: 51-54.

\section{Author' biography}

First \& corresponding author :

Mrs. Ioana Maria Curitianu.

Academic Qualification: PhD in Physical Education and Sports

Profession: Assistant PhD (Transilvania University - Faculty of Physical Education and Mountain Sports, Department of Physical Education and Special Motility)

Second Author: Mrs Elena Balint

Academic Qualification: PhD in Physical Education and Sports;

Profession: Professor (Transilvania University - Faculty of Physical Education and Mountain Sports, Department of Physical Education and Special Motility) 